\title{
The Particularity of Dilated Cardiomyopathy in Children about 45 Cases

\author{
Ahmed Ghazaly ${ }^{*}$, Lina Rachid, Mohamed Eljamili, Saloua Elkarimi, Mustapha El Hattaoui
}

Department of Cardiology and Pediatric, Mohamed VI University Hospital Center of Marrakech, Morocco

DOI: $10.36347 /$ sasjm.2020.v06i02.011

| Received: 12.02 .2020 | Accepted: 20.02.2020 | Published: 27.02 .2020

*Corresponding author: Ghazaly Ahmed

Abstract

Original Research Article

Introduction: Dilated cardiomyopathy is the most common form of pediatric cardiomyopathy. It's a myocardial disorder characterized by an alteration of the contraction of the left ventricular. Methodology: This was a descriptive and analytic retrospective study among 45 children across the pediatric and cardiology Departments of the Mohamed VI university hospital center of Marrakech. Results: The average age was 3 years. The predominant sex was male. The heart failure (HF) was the most frequent presentation in this study (31 cases). Trans-thoracic echocardiography showed a dilated left ventricle and an alterated ejection fraction in all cases. It was severe among 21 patients (45\%), mid-range in 13 cases (29\%), and moderate in 9cases (26\%). The most of patients had a standard laboratory test, an etiological biology test of the dilated cardiomyopathy. The most frequent etiology in our study was viral myocarditis in 20 cases. The evolution was favorable with medical therapy in 20 patients. Eight patients died and seven child lost to follow up. Discussion: Dilated cardiomyopathy is the most common form of cardiomyopathy and the leading cause of heart transplantation in children. The prognosis is severe since we observe a mortality of more than $50 \%$ at five years. Echocardiography is the most used mode of exploration. It makes it possible to highlight dilation with the increase in the left ventricular diameter and the decrease in the fraction of left ventricular ejection .The etiological diagnostic approach is guided by the circumstances of the onset of CMD. The therapy of CMD is that of left heart failure, and consists of the combination of the maximum tolerated dose of an ACE inhibitor, a diuretic, a beta-blocker and spironolactone. Conclusion: Dilated cardiomyopathy is frequent disease among children. In pediatric population, we must eliminate first a secondary cause and then search a metabolic and genetic disease.

Keyword: Dilated cardiomyopathy; children, Echocardiography; transplantation.

Copyright @ 2020: This is an open-access article distributed under the terms of the Creative Commons Attribution license which permits unrestricted use, distribution, and reproduction in any medium for non-commercial use (NonCommercial, or CC-BY-NC) provided the original author and source are credited.

\section{INTRODUCTION}

Dilated cardiomyopathy is the most common form of pediatric cardiomyopathy. It's a myocardial disorder characterized by a direct disorder of the cardiac muscle, alteration of the contraction of the left ventricular $(\mathrm{LV})$ or both ventricles. The diastolic dysfunction is variable. Patients with disease due to endocrine, drug toxicity, congenital, valvar and other causes were excluded.

The aim of this study is to determine the particularity of the epidemiology, the therapy, and the evolution of the dilated cardiomyopathy among children in the Mohamed VI university hospital center of Marrakech.

\section{MATERIALS AND METHODS}

This was a descriptive and analytic retrospective study among 45 children across the pediatric and cardiology

Departments of the Mohamed VI university hospital center of Marrakech over a period of 7 years from January 2012 to December 2019.

\section{RESULTS}

In the current study, the average age was 3 years. The younger had 4 months and the older 14 years. The predominant sex was male (Figure $1 \& 2$ ). 


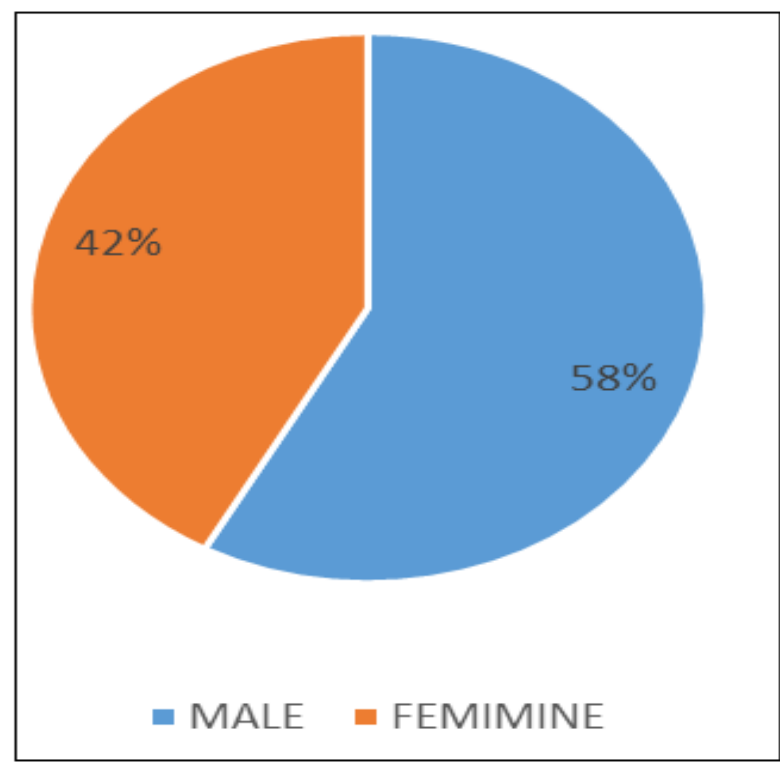

Fig-1: Distribution of patients by sexes

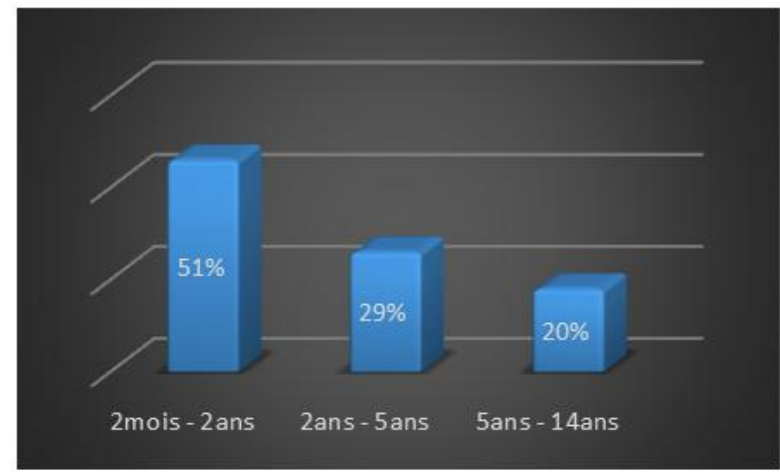

Fig-2: Distribution of patients by age group

The heart failure (HF) was the most frequent presentation in this study (31 cases).

Two patients was followed for Duchene muscular dystrophy, four patients for pneumonia and eight patients for viral bronchiolitis (Figure-3).

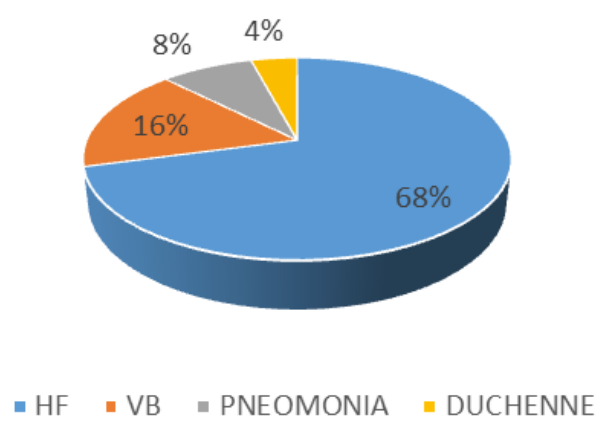

Fig-3: Distribution of patients by discovery circumstances

The chest X-ray showed an increased cardiothoracic ratio in all patients. It was often associated with the radiological signs of heart failure, pulmonary alveolar condensation or thoracic distension in some cases.

Trans-thoracic echocardiography showed a dilated left ventricle and an alterated ejection fraction in all cases. It was severe among 21 patients (45\%), midrange in 13 cases $(29 \%)$, and moderate in 9cases $(26 \%)$. A functional mitral regurgitation in 35 patients. A pulmonary hypertension in 30 cases. Dilated right chambers in 25 cases with systolic dysfunction in 18 patients (Figure-4).

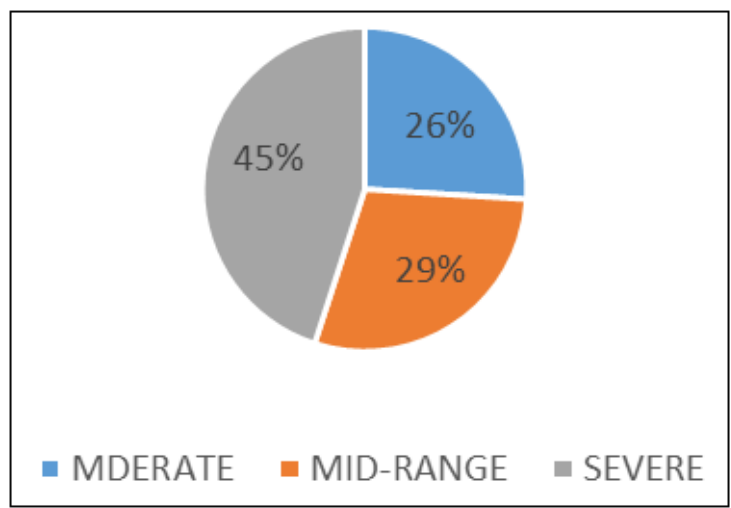

Fig-4: Distribution of patients by ejection fraction

The most of patients had a standard laboratory test, an etiological biology test of the dilated cardiomyopathy: phosphor-calcic, thyroid test, immunological tests, viral serology and L-carnitine dosage.

CPK test, EMG and muscle biopsy in six cases.

The most frequent etiology in our study was probable viral myocarditis in 20 cases.

Two cases of Duchene muscular dystrophy, three cases of $\mathrm{L}$ carnitine deficit, two cases of familiar dilated cardiomyopathy.

One case of anticorps anti phospholipides syndrome (APLS) and 17 cases was idiopathic (Figure$5)$.

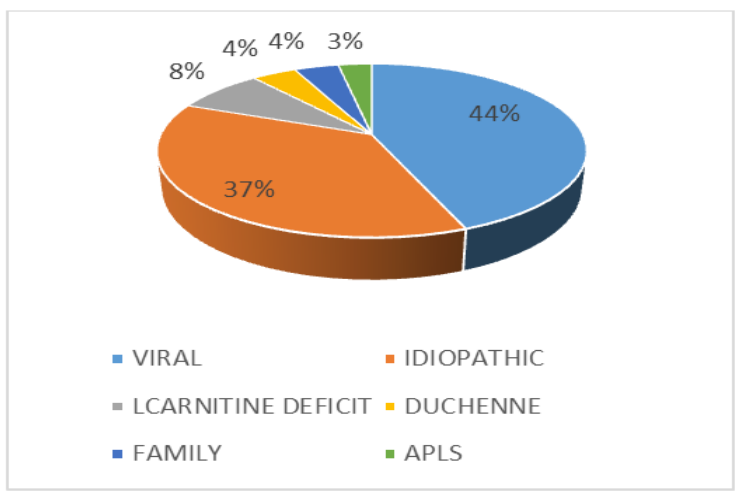

Fig-5: Etiology of CMD 
Our patients was treated by medical therapy based on digoxin, diuretic, beta-blockers and ACE inhibitors.

The Three cases of $\mathrm{L}$ carnitine deficit were managed by supplementation. The corticoids was prescribed in one case of APL syndrome.

The evolution was favorable with medical therapy in 20 patients and total recovery of the ejection fraction in 8patients; stationary in 10 cases.

A girl with very severe LV dysfunction had a heart transplantation, but died after 3 years of his transplantation.

Four patients were complicated by ischemic stroke, eight patients died and seven child lost to follow up (Figure-6).

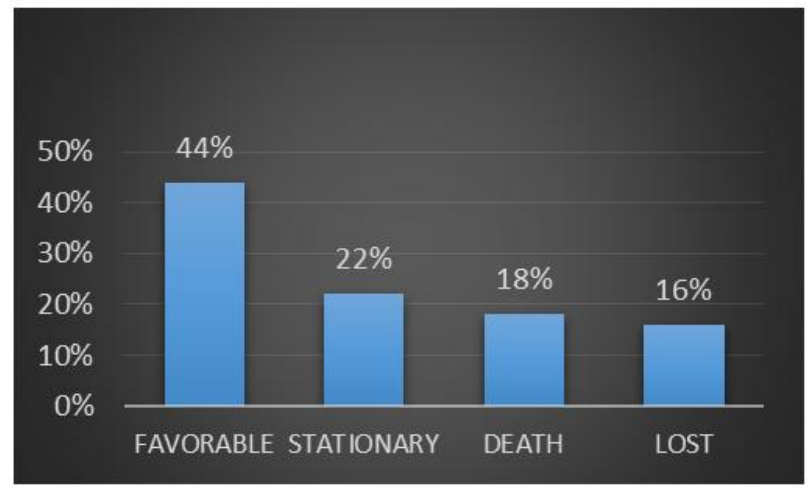

Fig-6: Evolution of patients

\section{DISCUSSION}

Dilated cardiomyopathy is the most common form of cardiomyopathy [1] and the leading cause of heart transplantation in children [2]. Epidemiological data concerning CMD indicate a prevalence of $1 / 2500$ people. The prognosis is severe since we observe a mortality of more than $50 \%$ at five years [3].

This disease can be identified incidentally in an asymptomatic patient during a preoperative check-up or in the presence of ECG abnormalities and / or on the chest x-ray.

Functional symptoms include exertional or paroxysmal dyspnea (nocturnal, decubitus), palpitations and / or chest pain associated with signs of right ventricular failure, peripheral edema with weight gain, hepatitis pain.

The ECG may show sinus tachycardia, atrial fibrillation or, more rarely, ventricular rhythm disturbances.

Echocardiography is the most used mode of exploration, it makes it possible to highlight dilation with the increase in the left ventricular diameter (or biventricular), the decrease in the fraction of left ventricular ejection (reflecting the alteration systolic function) and cardiac output indices.

The etiological diagnostic approach is guided by the circumstances of the onset of CMD, the examination and a full clinical examination. The biological assessment systematically includes an inflammatory assessment, sedimentation rate (VS), C reactive protein (CRP), a blood count with eosinophil count, a CPK test, high in certain genetic forms, of vitamin B of thyroid stimulating hormone (TSH), serum calcium, serum iron and ferritin.

Depending on the data from the interrogation and the clinic, it is supplemented by an autoimmune assessment, especially if suspected systemic lupus erythematosus, and infectious serology's, which should not be systematic and exhaustive but oriented, especially in search of an active chronic infection requiring specific treatment, except in cases where CMD appears subacutely in the aftermath of myocarditis, the serological balance then having to be complete, the antibody titers clearly high or the presence immunoglobulin $\mathrm{M}(\mathrm{IgM})$ signs of a recent infection.

An endocrine and / or nutritional assessment, which may include the dosage of prealbumin, selenium, carnitine may also be necessary.

As for the genetic assessment, it is only requested in the presence of a known familial disorder or found during the interrogation. The yield from genetic analysis is low, a mutation being found only in around $20 \%$ of familial forms [3]. The evolution of dilated cardiomyopathy is carried out conventionally towards the progressive deterioration of the cardiac function with phases of remission and more or less prolonged relapses. A quarter of patients die within the year of their first admission to cardiology and half will die within five years [4].

The therapy of CMD is that of left heart failure, and consists of the combination of the maximum tolerated dose of an ACE inhibitor, a diuretic, a beta-blocker and spironolactone $[4,5]$.

Concerning the data of some series of the literature (Table-1), a male predominance has been reported with an average age around 3 years, which joins the results of our series. Viral etiology was the main cause of CMD in the literature [6], but it remains unknown in most cases in most series [5].

The evolution in our study was favorable in $44 \%$; this can be explained by the predominance of viral etiology, which generally has, a favorable evolution with a lower mortality rate compared with the other series. On the other hand, we note a lower 
transplant rate in our study compared to the other series; for example: there is 1case having undergone transplantation in our series against nine patients in the Turkish series $[1,7,8]$.

Table-1: Data from some literary series

\begin{tabular}{|c|c|c|c|c|}
\hline SERIES & Middle Age & Sexe & Etiology & Evolution \\
\hline OUR SERIE & 3ans & Male & $\begin{array}{ll}\checkmark & \text { Viral }(45 \%) \\
\checkmark & \text { Myopathie }(7 \%) . \\
\checkmark & \text { L carnitine deficit }(7 \%) \\
\checkmark & \text { SAPL }(3 \%) \\
\checkmark & \text { Indefinite }(37 \%) .\end{array}$ & $\begin{array}{l}\text { Favorable }(45 \%) \text { : } \\
\text {-Mortality }(17 \%)\end{array}$ \\
\hline Sfaihi (TUNISIA, 2009) [2] & 3ans et 2 mois & Male & $\begin{array}{ll}\checkmark & \text { Viral }(25 \%) \\
\checkmark & \text { Indefinite }(50 \%)\end{array}$ & $\begin{array}{l}\text { Favorable }(25 \%) \\
\text { Mortality }(12 \%)\end{array}$ \\
\hline $\begin{array}{l}\text { Denizhan Bagrul (Turqey, } \\
\text { 2016) }\end{array}$ & Entre 1 mois et 17 ans & Male & $\begin{array}{ll}\checkmark & \text { Viral }(21 \%) \\
\checkmark & \text { Family }(14 \%) \\
\checkmark & \text { Idiopathic }(66 \%) .\end{array}$ & $\begin{array}{l}\text { Mortality }(33 \%) \\
\text { Transplantation }(16 \%)\end{array}$ \\
\hline Towbin JA (USA, 2006) [3] & 15 mois & Male & $\begin{array}{ll}\checkmark & \text { Viral }(44 \%) \\
\checkmark & \text { Neuro-muscular diseases } \\
& (26 \%)\end{array}$ & $\begin{array}{l}\text { Mortality }(31 \%) \\
\text { Transplantation }(46 \%)\end{array}$ \\
\hline
\end{tabular}

\section{CONCLUSION}

Dilated cardiomyopathy is frequent disease among children. The identification of the incidence is very difficult and need a national register.

In pediatric population, we must eliminate first a secondary cause and then search a metabolic and genetic disease, which is usually difficult to do.

Despite the progress of methods of diagnosis, and the tools of management, dilated cardiomyopathy have a poor prognosis.

\section{REFERENCES}

1. Towbin JA, Lowe AM, Colan SD, Sleeper LA, Orav EJ, Clunie S, Messere J, Cox GF, Lurie PR, Hsu D, Canter C. Incidence, causes, and outcomes of dilated cardiomyopathy in children. Jama. 2006 Oct 18;296(15):1867-76.

2. Williams GD, Hammer GB. Cardiomyopathy in childhood. Curr Opin Anesthesiol, 2011; 24:289300 .
3. Galinier M, Lairez O, Roncalli J, Dumonteil N, Maury P, Pathak A, Biendel C. Primary and secondary dilated cardiomyopathies. 2011 Elsevier Masson SAS: 11-044-C-10.

4. Richard P, Fressart V, Charron P, Hainque B. Genetics of inherited cardiomyopathies. Pathologie-biologie. 2010 Oct;58(5):343-52.

5. Maalej B, Gargouri L, Abid D, Weli M, Feki W, Fourati H, Mnif Z, Kamoun S, Abid L, Mahfoudh E. La cardiomyopathie dilatee de l'enfant dilated cardiomyopathy in childhood. Journal de l'Information Médicale de Sfax. 2018 Jun:18.

6. Myocardial disease in children. Encycl Méd Chir, Pediatrics, 4-071-A-41, Cardiology, 11-022-A-10, 2000, 11.

7. Sfaihi L, Majdoub I, Gargouri L, Kalamoun I, Kamoun T, Hachicha M. Etiological and evolutionary aspects of dilated cardiomyopathies in children. Sfax, Tunisia.

8. Bagrul D, Pac FA, Koca S, Ece I, Kocabeyoglu S, Pac M. PP-163 Dilated Cardiomyopathy in Children: Clinical Characteristics, Prognostic Factors and Outcome. American Journal of Cardiology. 2016 Jun 2;117:S99. 